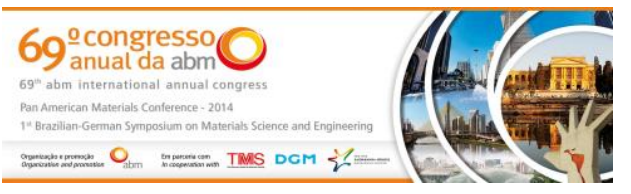

Tema: Tratamento térmico

\title{
ESTUDO DE PRECIPITAÇÃO DE FASE SIGMA EM UM AÇO INOXIDÁVEL DUPLEX UNS S31803 (SAF 2205) PELO MÉTODO NÃO DESTRUTIVO DE RUÍDO MAGNÉTICO BARKHAUSEN*
}

\author{
Paula Cristina Petriz Monteiro ${ }^{1}$ \\ Marcos Flávio de Campos ${ }^{2}$ \\ Célio de Jesus Marcelo ${ }^{3}$ \\ Carlos Roberto Xavier ${ }^{4}$ \\ Manuel Alberteris Campos 5 \\ Linilson Ribeiro Padovese ${ }^{6}$
}

\section{Resumo}

O Aço Inoxidável Duplex (AID) possui duas fases com propriedades magnéticas distintas, ferrita e austenita. Quando submetido a elevadas temperaturas, o AID pode apresentar em sua estrutura a fase intermetálica sigma que degrada suas propriedades e limitam a sua utilização. Este trabalho tem como objetivo utilizar a técnica de Ruído Magnético Barkhausen (RMB), para caracterizar amostras de AID SAF2205 com precipitados de fase sigma. Foram realizadas análises metalográficas, detecção do teor de ferrita através do ferritoscópio e difração de raios- $x$ para validação dos resultados. Pode-se verificar que o ensaio de RMB é adequado para avaliar teores elevados de fase sigma neste aço.

Palavras-chave: Aço Inoxidável Duplex; Fase sigma; Ruído Magnético Barkhausen.

\section{STUDY OF PRECIPITATION SIGMA PHASE IN A DUPLEX STAINLESS STEEL UNS S31803 (SAF 2205) NON DESTRUCTIVE METHOD FOR MAGNETIC NOISE BARKHAUSEN}

\section{Abstract}

The Duplex Stainless Steel (DSS) has two phases with distinct magnetic properties, ferrite and austenite. When subjected to high temperatures, the DSS may have in its structure a sigma intermetallic phase which degrades its properties and limit their use. This paper aims to use the technique Magnetic Barkhausen Noise (MBN), to characterize samples with DSS SAF2205 precipitated sigma phase. Metallographic analysis, detection of ferrite content and ferritoscope by $\mathrm{x}$-ray diffraction for validation of the results were performed. One can check that the MBN test is suitable for evaluating large amounts of sigma phase in this steel.

Keywords: Duplex Stainless Steel; Sigma phase; Magnetic Barkhausen Noise.

1 Engenheira, Mestranda, PPGEM, UFF, Volta Redonda, RJ, Brasil.

2 Engenheiro, D.Sc., Professor, VEM e PPGEM, UFF, Volta Redonda, RJ, Brasil.

3 Técnico em mecânica, Técnico, Laboratório de Ciências Mecânicas, UFF, Volta Redonda, RJ, Brasil.

4 Engenheiro, D.Sc., Professor, UNIFOA, Volta Redonda, RJ, Brasil.

5 Físico, D.Sc., Pós-Doutorando, PPGEM, UFF, Volta Redonda, RJ, Brasil.

6 Engenheiro, D.Sc., Professor, Departamento de Engenharia Mecânica, USP, São Paulo, SP, Brasil.

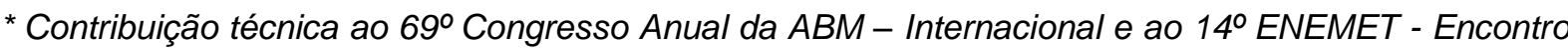
Nacional de Estudantes de Engenharia Metalúrgica, de Materiais e de Minas, 21 a 25 de julho de 2014, São Paulo, SP, Brasil.
} 


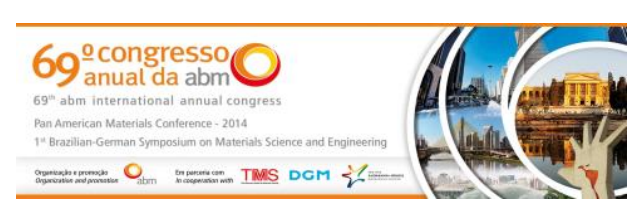

\section{INTRODUÇÃO}

Com o desenvolvimento das indústrias offshore, químicas e petroquímicas surgiu a necessidade de materiais que suportassem uma elevada solicitação mecânica e alta resistência a corrosão, neste contexto os aços inoxidáveis duplex tem sido utilizados.

Os aços inoxidáveis duplex são constituídos de uma estrutura mista de ferrita e austenita. A quantidade exata de cada fase é uma função da composição e tratamento térmico, a maioria das ligas contém quantidades iguais de cada fase devido ao equilíbrio de elementos que estabilizam a austenita ( $, \mathrm{N}, \mathrm{Ni}, \mathrm{Cu}$ e $\mathrm{Mn}$ ) e ferrita (Cr, Mo e Si) [1].

De acordo com Pohl et al. [2] na faixa de temperatura de $650-950^{\circ} \mathrm{C}$ podem surgir precipitados intermetálicos nos aços inoxidáveis duplex devido a quantidade e distribuição dos elementos de liga na fase ferrítica e austenítica. Precipitados de nitretos, fase sigma $(\sigma)$ e fase chi $(X)$ influenciam as propriedades mecânicas assim como as propriedades corrosivas, causando fragilização no aço e levando a uma rápida redução da tenacidade.

A estrutura dos aços inoxidáveis duplex possui duas fases com propriedades magnéticas distintas. O material em seu estado solubilizado apresenta características ferromagnéticas, a mesma apresentada pela fase ferrítica, enquanto que a fase austenítica apresenta um comportamento paramagnético, Loureiro [3].

Quando materiais ferromagnéticos são submetidos a campos magnéticos variáveis, a variação da indução ocorre de forma descontínua em decorrência da movimentação das paredes dos domínios magnéticos. Esses saltos discretos da indução produzem pulsos magnéticos conhecidos como Ruído Magnético de Barkhausen (RMB). O RMB é sensível a alterações microestruturais, tensões e deformações plásticas [4].

O trabalho tem como objetivo avaliar a utilização da técnica de (RMB) como ferramenta de inspeção não destrutiva na caracterização de aço inoxidável duplex com precipitados de fase sigma. Para induzir a precipitação da fase deletéria sigma foram realizados tratamentos de envelhecimento isotérmico trabalhando com temperaturas de $750^{\circ} \mathrm{C}$ e $850^{\circ} \mathrm{C}$ em diferentes tempos. As amostras envelhecidas foram então analisadas pelo método de RMB. As variações resultantes no ruído foram então comparadas com outras técnicas (análise metalográfica, difração de raios-X, e medição do teor de ferrita) para obtenção de informações quanto à microestrutura resultante.

\section{MATERIAIS E MÉTODOS}

O material em estudo foi o Aço Inoxidável Dúplex UNS S31803 (SAF 2205) na condição inicial de chapa laminada a quente de $4 \mathrm{~mm}$ de espessura com composição química descrita na Tabela 1.

Tabela 1. Composição Química de amostras do aço em estudo

\begin{tabular}{cccccccccc}
\hline $\mathbf{C}$ & $\mathbf{C r}$ & $\mathbf{M n}$ & $\mathbf{M o}$ & $\mathbf{N i}$ & $\mathbf{S i}$ & $\mathbf{S}$ & $\mathbf{P}$ & $\mathbf{N}_{2}$ & $\mathbf{O}_{2}$ \\
\hline \multirow{2}{*}{0,0155} & \multirow{2}{*}{22,753} & \multirow{2}{*}{1,8357} & \multirow{2}{*}{3,0147} & \multirow{2}{*}{5,4682} & \multirow{2}{*}{0,3238} & $\begin{array}{c}7 \\
\mathrm{ppm}\end{array}$ & $\begin{array}{c}256 \\
\mathrm{ppm}\end{array}$ & $\begin{array}{c}1610 \\
\mathrm{ppm}\end{array}$ & $\begin{array}{c}35 \\
\mathrm{ppm}\end{array}$ \\
\hline
\end{tabular}

Fonte: Aperam Inox América do Sul

\footnotetext{
* Contribuição técnica ao $69^{\circ}$ Congresso Anual da ABM - Internacional e ao 14ํㅡㄹ ENEMET - Encontro Nacional de Estudantes de Engenharia Metalúrgica, de Materiais e de Minas, 21 a 25 de julho de 2014, São Paulo, SP, Brasil.
} 


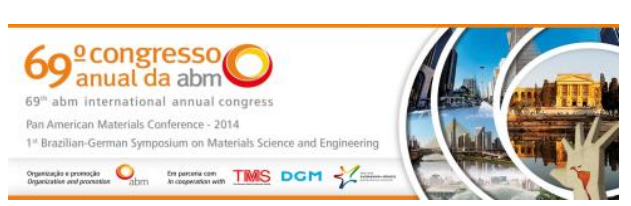

Da chapa foram obtidas 22 amostras de $71 \mathrm{~mm} \times 34 \mathrm{~mm}$ de área que foram unidas duas a duas por pontos de solda em dois estremos totalizando assim 11 amostras.

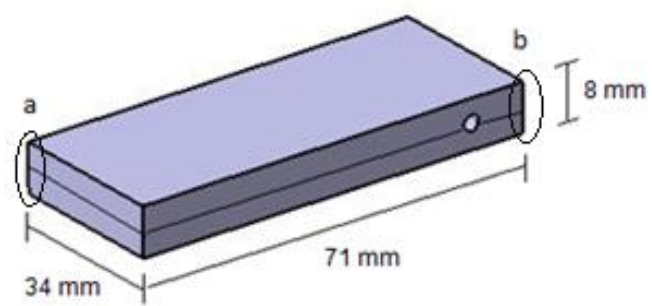

Figura 1. Configuração da amostra em estudo. Nos extremos a e b ocorreu a solda.

Dez amostras foram submetidas ao tratamento térmico de envelhecimento isotérmico com o objetivo de induzir a precipitação de fase sigma em duas séries de temperaturas, $750^{\circ} \mathrm{C}$ e $850^{\circ} \mathrm{C}$, em diferentes tempos como descritos na Tabela 2.

Tabela 2. Condições das amostras no tratamento térmico

\begin{tabular}{ccc}
\hline Amostra & Tempo (min) & ${\text { Temperatura }\left({ }^{\circ} \mathbf{C}\right)}$ \\
\hline 751 & 1 & 750 \\
\hline 753 & 3 & 750 \\
\hline 755 & 5 & 750 \\
\hline 7510 & 10 & 750 \\
\hline 7520 & 20 & 750 \\
\hline 851 & 1 & 850 \\
\hline 853 & 3 & 850 \\
\hline 855 & 5 & 850 \\
\hline 8510 & 10 & 850 \\
\hline 8520 & 20 & 850 \\
\hline
\end{tabular}

Para as duas séries de tratamento térmico utilizou-se forno Mufla. Foi designado como amostra 0 , aquela que não foi submetida ao tratamento térmico. Nas amostras 751, 7510, 7520, 851, 8510, 8520 foram inseridos termopares a fim controlar a variação da temperatura durante o tratamento térmico. O termopar foi ligado ao aparelho Spider 8, que possui portas de entrada para os dados vindos do termopar, enviando-os ao programa Catman 4.5, que capta e armazena os dados recebidos da temperatura com o tempo decorrido. Primeiramente o forno foi aquecido a $750^{\circ} \mathrm{C}$, onde foram inseridas as amostras 751, 753, 755, 7510 e 7520. As amostras foram retiradas cada uma delas conforme seus respectivos tempos de tratamento térmico. $\mathrm{O}$ mesmo procedimento foi realizado nas amostras submetidas à temperatura de $850^{\circ} \mathrm{C}$.

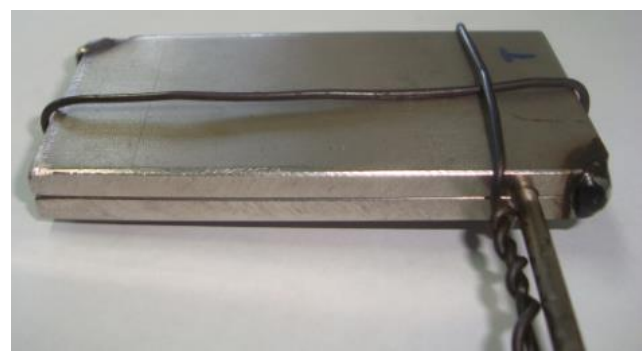

Figura 2. Amostra com termopar.

\footnotetext{
* Contribuição técnica ao $69^{\circ}$ Congresso Anual da ABM - Internacional e ao 14ํㅡㄹ ENEMET - Encontro Nacional de Estudantes de Engenharia Metalúrgica, de Materiais e de Minas, 21 a 25 de julho de 2014, São Paulo, SP, Brasil.
} 


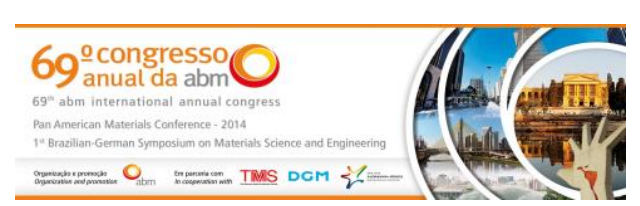

Ao final do tratamento térmico as amostras foram submetidas ao resfriamento rápido em água. Os pontos de solda que permitiam a união das amostras foram removidos ocorrendo a separação da mesma, sendo reservada uma para a análise do RMB, medição do teor de ferrita e difração de raios-X e outra destinada para a preparação metalográfica.

Para a amostra sem tratamento térmico foi realizado o ataque químico com Behara II, constituído de $1000 \mathrm{ml}$ de água destilada, $200 \mathrm{ml}$ de ácido clorídrico (HCl) e, a cada $100 \mathrm{ml}$ desta solução estoque, adicionou-se $0,3 \mathrm{~g}$ de metabissulfito de potássio $\left(\mathrm{K}_{2} \mathrm{~S}_{2} \mathrm{O}_{5}\right)$ a fim de caracterizar o material como recebido. Após o tratamento térmico do material realizou-se o ataque eletrolítico seletivo, que revela a fase sigma (rica em cromo) e deixa as fases austenita e ferrita praticamente não atacadas. A solução utilizada foi hidróxido de potássio $(\mathrm{KOH})$ a $10 \%(100 \mathrm{~g}$ de $\mathrm{KOH}$ e $1 \mathrm{~L}$ de água destilada).

A técnica de Difração de Raios-X (DRX) foi utilizada para caracterizar as fases presentes nas diferentes amostras em estudo, o equipamento utilizado foi 0 Difratômetro Shimadzu XRD-6.000. As amostras foram analisadas sem preparação metalográfica numa varredura de $20^{\circ}$ a $160^{\circ}$. Essa identificação foi realizada utilizando-se padrões difratométricos para cada fase utilizando-se o software PowderCell 2.4. Foram realizadas sobreposições dos picos obtidos pela difração de raios x com o padrão do software identificando assim os índices de Miller dos planos atômicos de difração.

Através do ferritoscópio Fischer, foi possível medir a fração volumétrica de ferrita nas amostras envelhecidas.

Para a análise do Ruído Magnético Barkhausen (RMB) foi utilizado o equipamento Barktech, totalmente desenvolvido pelo Laboratório de Dinâmica e Instrumentação LADIN, da Universidade de São Paulo. O equipamento é composto de: um sensor (sonda), um computador de controle com software instalado (desenvolvido a partir da plataforma LabVIEW) e um conjunto excitador e condicionador de sinal.

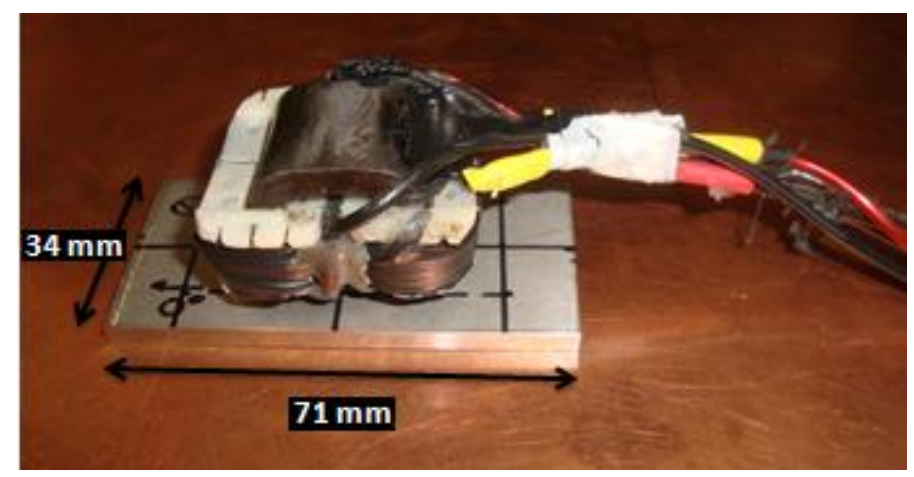

Figura 3. Detalhe da sonda posicionada sobre uma das amostras em estudo.

Procurou-se avaliar características microestruturais do aço inoxidável com a variação da quantidade de ferrita em cada amostra. As técnicas auxiliares descritas anteriormente foram utilizadas para buscar variações das fases.

\section{RESULTADOS E DISCUSSÃO}

Após o ataque químico Behara II, na amostra sem tratamento térmico, observa-se a micrografia na figura 4 onde a fase ferrita se apresenta com tonalidade mais escura devido à ação do reagente, já a austenita aparece com coloração mais clara.

\footnotetext{
* Contribuição técnica ao $69^{\circ}$ Congresso Anual da ABM - Internacional e ao 14ํㅡㄹ ENEMET - Encontro Nacional de Estudantes de Engenharia Metalúrgica, de Materiais e de Minas, 21 a 25 de julho de 2014, São Paulo, SP, Brasil.
} 

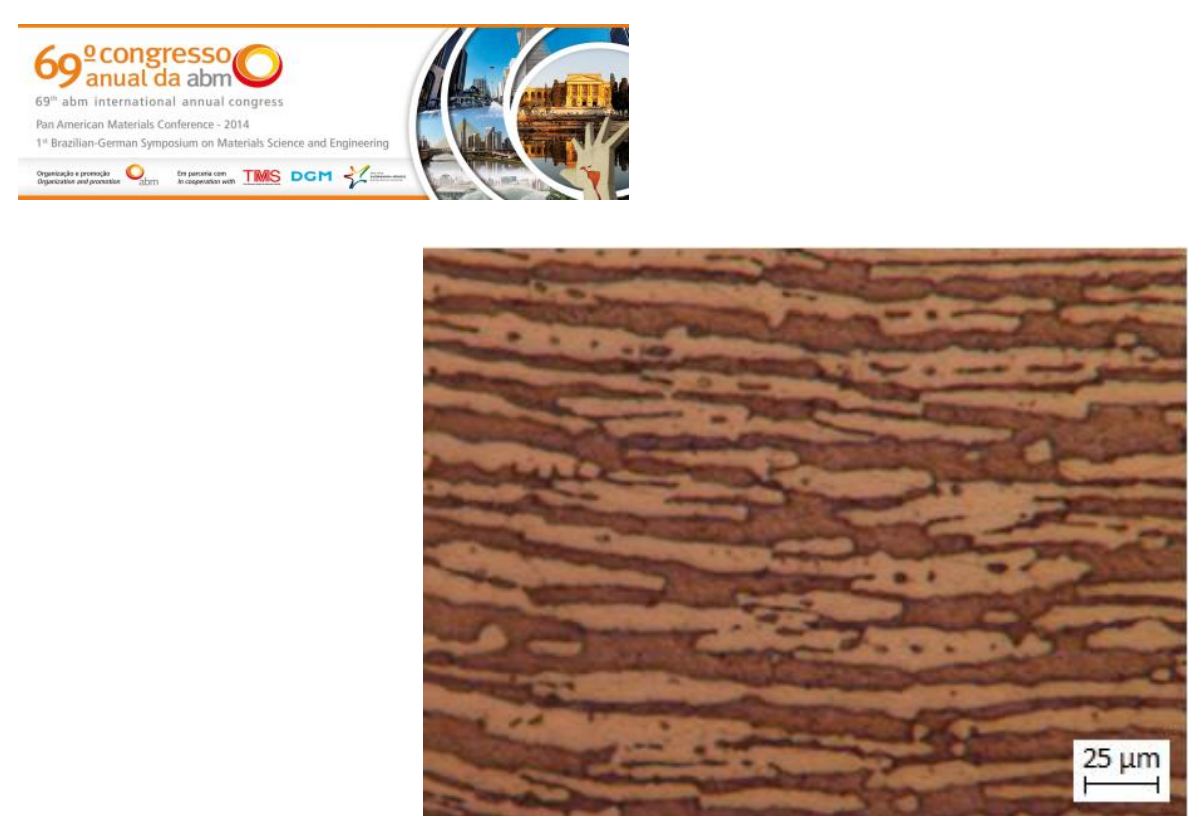

Figura 4. Micrografia da amostra não tratada termicamente. Ataque químico Behara II, aumento 1.000x.

É possível observar ilhas de austenita no interior da matriz ferrítica. Na Tabela 3 segue o resultado após a quantificação.

Tabela 3. Quantificação da amostra sem tratamento térmico

\begin{tabular}{cc}
\hline Fração de ferrita (\%) & Fração de austenita (\%) \\
\hline 48,6 & 51,4 \\
\hline
\end{tabular}

Nas Figuras 5 e 6 observam-se as micrografias após ataque eletrolítico seletivo das amostras tratadas a $750^{\circ} \mathrm{C}$ e $850^{\circ} \mathrm{C}$ respectivamente. Com este ataque foi revelada a fase sigma, que é rica em cromo. As micrografias indicam que a fase sigma aparece com coloração marrom permitindo assim medir a fração volumétrica de sigma. Segundo Michalska et al. [5], a fase intermetálica $\sigma$ é encontrada nas fronteiras dos grãos ferrita-austenita e no interior dos grãos ferríticos.

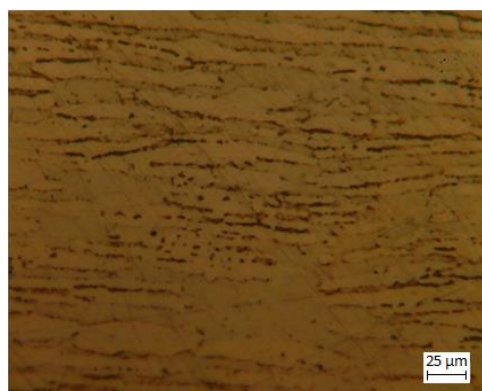

(a)

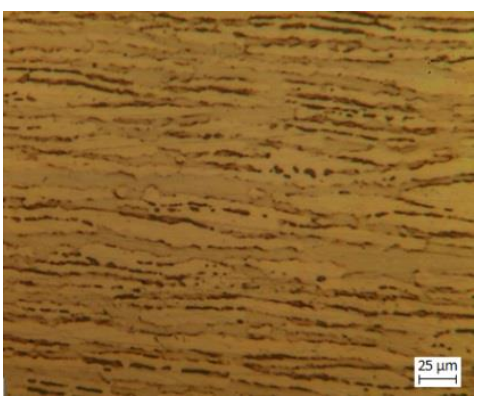

(b)

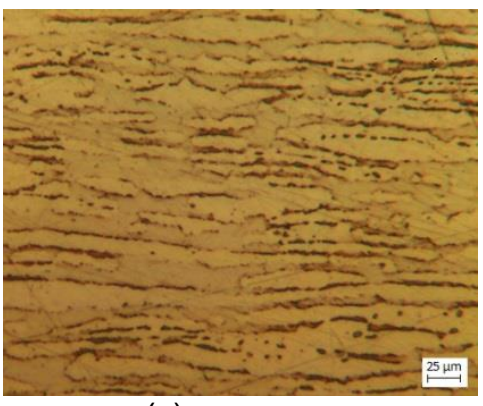

(c)

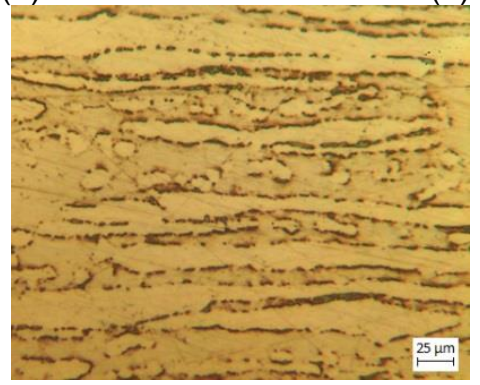

(d)

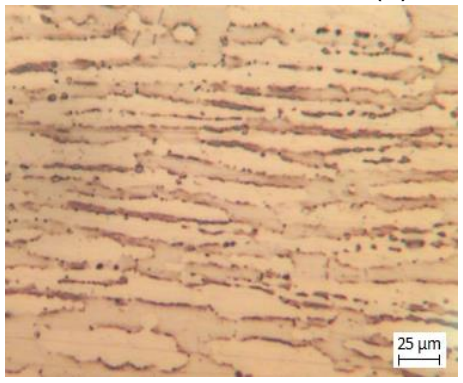

(e)

Figura 5. Micrografias das amostras 751 (a), 753 (b), 755 (c), 7510 (d), 7520 (e) envelhecidas a $750^{\circ} \mathrm{C}$ após ataque eletrolítico. Aumento 1.000x.

\footnotetext{
* Contribuição técnica ao 69 Congresso Anual da ABM - Internacional e ao 14 ENEMET - Encontro Nacional de Estudantes de Engenharia Metalúrgica, de Materiais e de Minas, 21 a 25 de julho de 2014, São Paulo, SP, Brasil.
} 


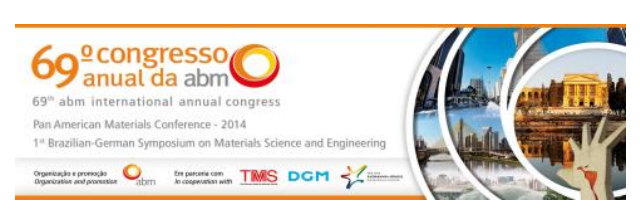

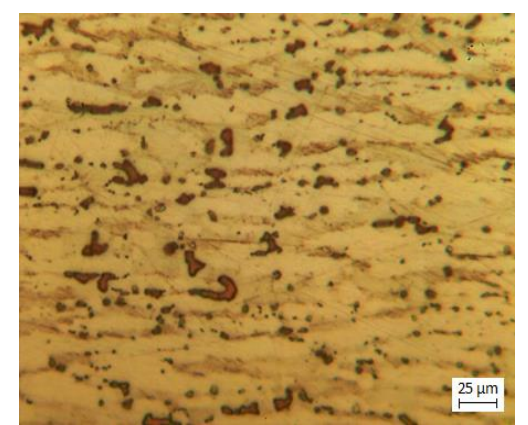

(a)

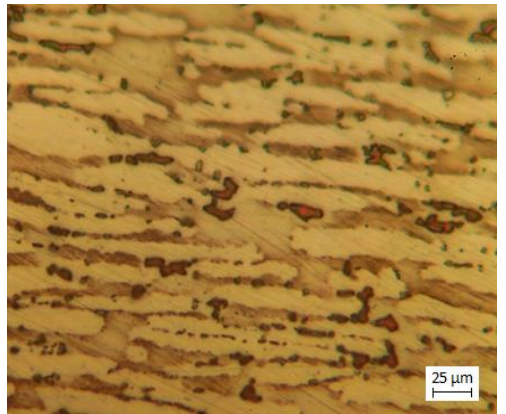

(b)

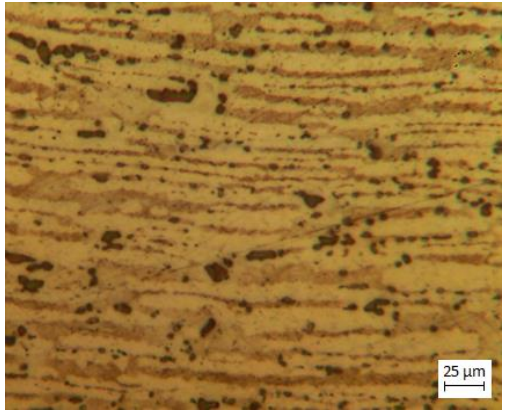

(c)

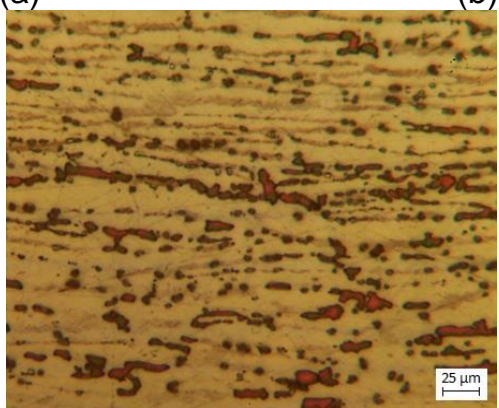

(d)

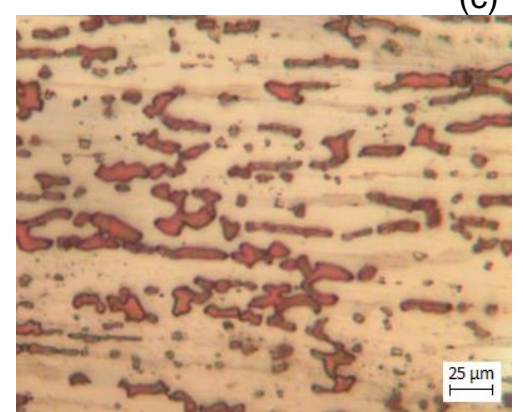

(e)

Figura 6. Micrografias das amostras 851 (a), 853 (b), 855 (c), 8510 (d), 8520 (e) envelhecidas a $850^{\circ} \mathrm{C}$ após ataque eletrolítico. Aumento 1000x.

$\mathrm{Na}$ Tabela 4 pode ser visto os resultados de quantificação de fase sigma após ataque eletrolítico nas duas séries de amostras em estudo. Na Figura 7 é possível evidenciar que o teor de sigma aumenta com o tempo nas duas séries de temperaturas. Segundo Romana [6], este aço quando exposto a temperaturas de $700^{\circ} \mathrm{C}$ a $900^{\circ} \mathrm{C}$ por um longo período de tempo apresenta maiores teores de fase sigma. Portanto se o material permanecesse exposto por mais tempo ao tratamento de envelhecimento, apresentaria volumes ainda maiores de sigma em sua estrutura.

Maiores teores de fase sigma são encontrados nas amostras expostas a temperatura de $850^{\circ} \mathrm{C}$. Trabalho anterior de Magnabosco [7] mostra que a maior cinética de formação da fase sigma ocorre a $850^{\circ} \mathrm{C}$.

Tabela 4. Percentuais de fase sigma

\begin{tabular}{cccc}
\hline Amostra & \% sigma & Amostra & \% sigma \\
\hline 751 & 3,5 & 851 & 5,3 \\
\hline 753 & 5,9 & 853 & 7,1 \\
\hline 755 & 6,5 & 855 & 9,2 \\
\hline 7510 & 9,2 & 8510 & 12,6 \\
\hline 7520 & 11,9 & 8520 & 14,3 \\
\hline
\end{tabular}

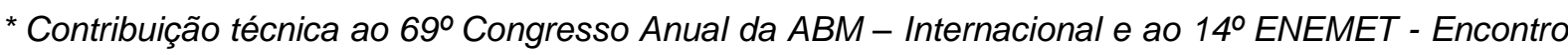
Nacional de Estudantes de Engenharia Metalúrgica, de Materiais e de Minas, 21 a 25 de julho de 2014, São Paulo, SP, Brasil.
} 

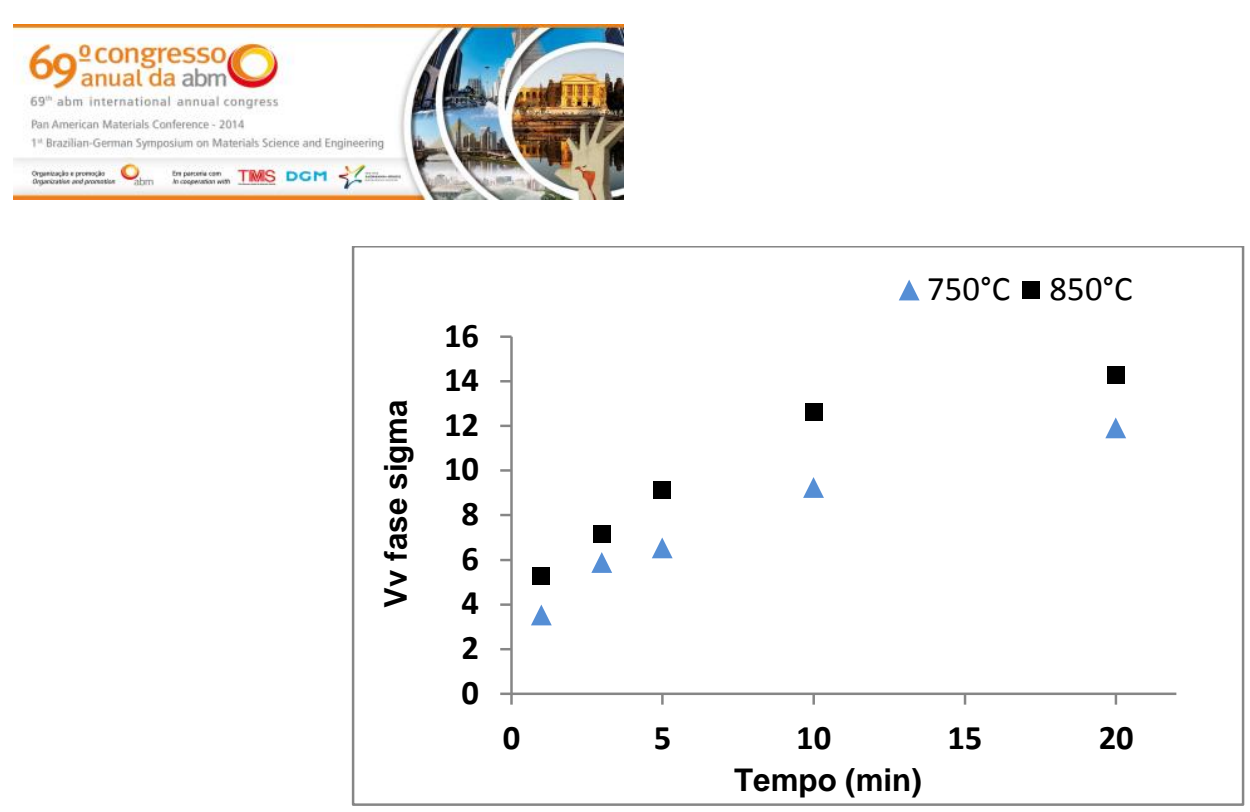

Figura 7. Evolução do percentual de fase sigma com o tempo de envelhecimento.

$\mathrm{Na}$ Tabela 5 pode ser visto a fração de ferrita nas amostras após análise com o ferritoscópio. Na figura 8 observa-se que a fração volumétrica de ferrita decresce progressivamente com o tempo e a temperatura do tratamento térmico. De acordo com Loureiro [3], o aumento do percentual de fase sigma acarreta uma diminuição do comportamento ferromagnético do aço duplex, devido à diminuição do percentual de ferrita na microestrutura do material. O valor de ferrita medido no ferritoscópio na amostra sem tratamento térmico $(38,17 \%)$ é inferior ao medido por metalografia $(48,60 \%)$. Para validar o resultado considera-se que o valor de ferrita é de 48,60, valor encontrado via metalografia, pois o ferritoscópio é uma técnica indireta podendo ocorrer variações do campo magnético.

Tabela 5. Fração volumétrica de ferrita nas diferentes amostras

\begin{tabular}{cccc}
\hline Amostra & \% ferrita & Amostra & \% ferrita \\
\hline 0 & 38,57 & - & - \\
\hline 751 & 31,24 & 851 & 23,99 \\
\hline 753 & 31,48 & 853 & 22,56 \\
\hline 755 & 30,52 & 855 & 20,76 \\
\hline 7510 & 29,16 & 8510 & 17,12 \\
\hline 7520 & 28,09 & 8520 & 13,38 \\
\hline
\end{tabular}

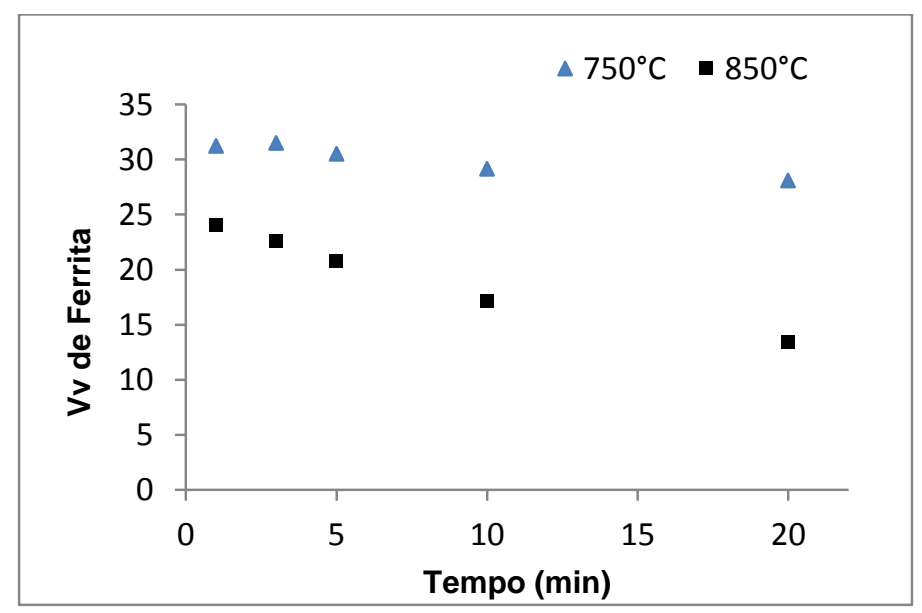

Figura 8. Frações volumétricas de ferrita após envelhecimento a $750^{\circ} \mathrm{C}$ e $850^{\circ} \mathrm{C}$.

A Figura 9 representa os resultados da quantificação das fases ferrita, sigma e austenita nas diferentes amostras usando o software PowderCell.

* Contribuição técnica ao $69^{\circ}$ Congresso Anual da ABM - Internacional e ao 14ํㅡㄹ ENEMET - Encontro Nacional de Estudantes de Engenharia Metalúrgica, de Materiais e de Minas, 21 a 25 de julho de 2014, São Paulo, SP, Brasil. 


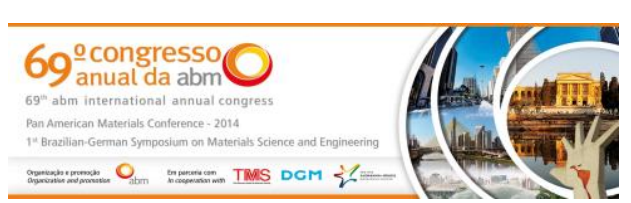

Em (a) a quantificação de ferrita por DRX se aproxima da quantificação por metalografia; já o teor de ferrita obtido por meio do ferritoscópio, por sem um método indireto, ficou com baixos teores de ferrita; igualmente observado na literatura, pois conforme Tavares et al. [8] o valor de ferrita medido no ferritoscópio é inferior ao medido por metalografia. Na figura (b) a quantificação via metalografia está muito distante dos demais métodos de análise, esperava-se que ela estivesse próxima à quantificação feita no DRX por serem dois métodos de análise direta.

Pode ser visto na Figura 11 o envelope de ruído para as amostras 0, 7520 e 8520.

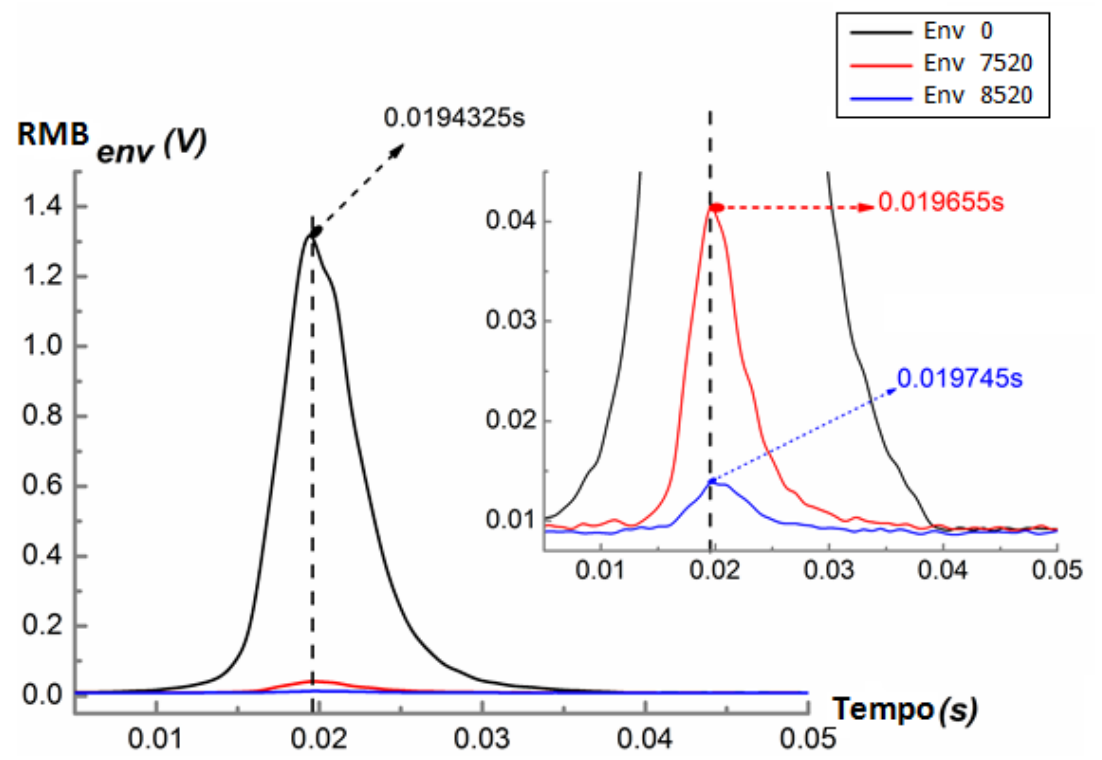

Figura 11. Envelope do RMB para as amostras 0,7520 e 8520 , com frequência de $10 \mathrm{~Hz}$.

Há uma queda significativa na amplitude do ruído ao comparar a amostra 0 (sem tratamento térmico) com as amostras 7520 e 8520 tratadas termicamente. A amostra 8520 por ter precipitado mais fase sigma, apresentou uma baixa voltagem, quase nula se comparada com a amostra sem tratamento térmico. Isto ocorreu porque a ferrita (ferromagnética) foi consumida ao precipitar a fase sigma (paramagnética) permitindo assim a queda no RMB. A amplitude máxima foi detectada na amostra 0 , sem tratamento térmico, pois apresenta teor elevado de ferrita, que é magnética, como era de se esperar. Segundo Normando et al. [9], a técnica de RMB é sensível a alterações em AID quando há formação de fase sigma devido ao tratamento térmico.

Na Figura 12 observa-se o envelope de RMB para as amostras tratadas a $750^{\circ} \mathrm{C}$ por $1,3,5$ e 10 minutos. De acordo com os resultados obtidos via metalografia quantitativa esperava-se uma queda no sinal magnético com o aumento do tempo de exposição da amostra no forno. O envelope de RMB não apresentou relação com aumento do tempo de tratamento térmico e redução da amplitude do ruído.

\footnotetext{
* Contribuição técnica ao $69^{\circ}$ Congresso Anual da ABM - Internacional e ao 14ํㅡㄹ ENEMET - Encontro Nacional de Estudantes de Engenharia Metalúrgica, de Materiais e de Minas, 21 a 25 de julho de 2014, São Paulo, SP, Brasil.
} 

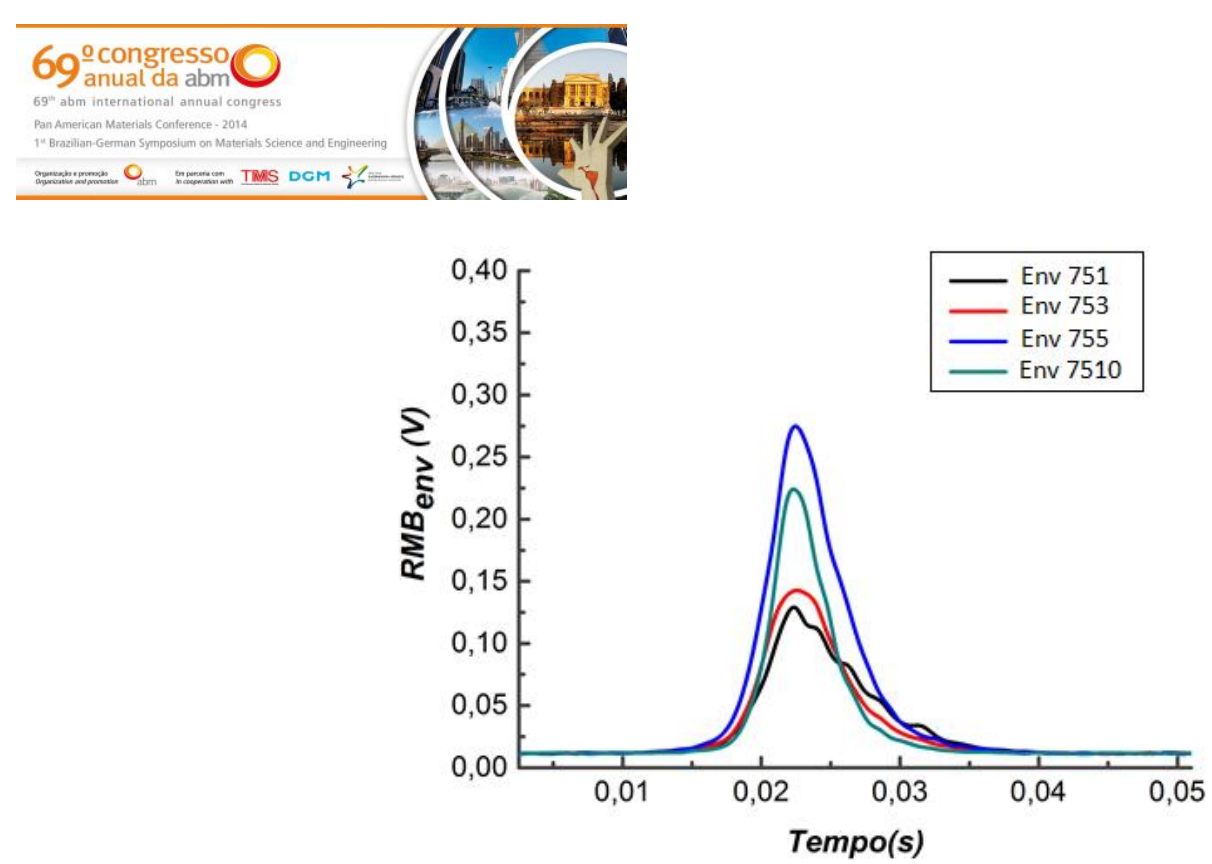

Figura 12. Envelope de RMB para amostras a $750^{\circ} \mathrm{C}$ em tempos de $1,3,5$ e 10 minutos.

$\mathrm{Na}$ Figura 13, para a série de amostras tratadas a $850^{\circ} \mathrm{C}$ por $1,3,5$ e 10 minutos também era esperada uma queda do sinal magnético com o aumento do tempo de exposição no forno. Analisando o envelope 8510 deveria ter uma menor amplitude, o que não foi verificado. O mesmo ocorreu para a amostra 851, como ela permaneceu menos tempo no forno, a amplitude deveria ter sido máxima o que não foi verificado.

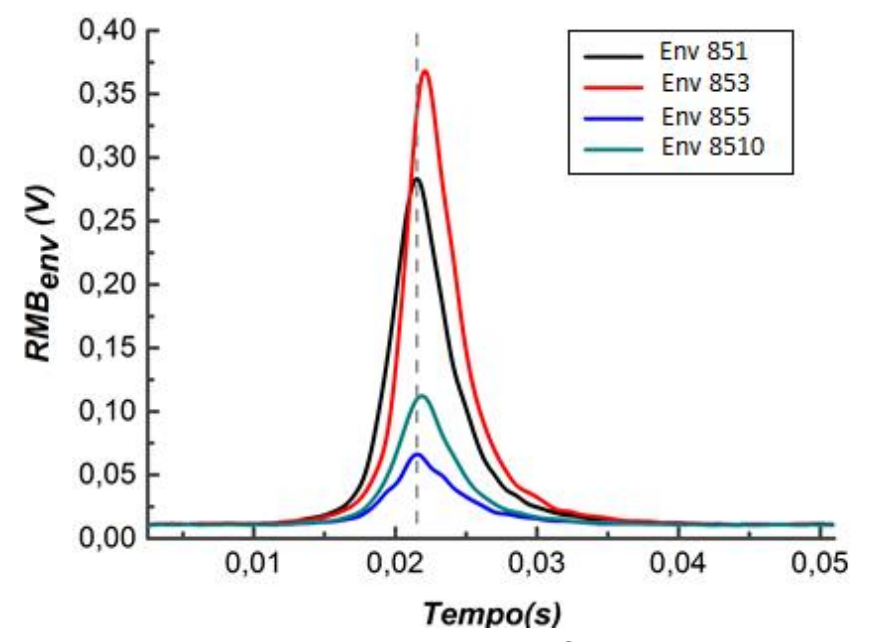

Figura 13. Envelope de RMB para amostras a $850^{\circ} \mathrm{C}$ em tempos de $1,3,5$ e 10 minutos.

\section{CONCLUSÃO}

Com o tratamento térmico de envelhecimento foi possível obter diferentes teores de fase sigma no material.

A utilização da metalografia quantitativa, difração de raios-x e ferritoscópio para as amostras em estudo serviram como base de comparação no ensaio de RMB. A medida por metalografia deveria ter apresentado valor próximo ao DRX, por serem dois métodos de análise direta. A ausência de fase sigma em algumas amostras após a quantificação por raios-x pode ser devido à interpretação do programa PowderCell, pois ele tem dificuldade de detectar frações volumétricas inferiores a $3 \%$.

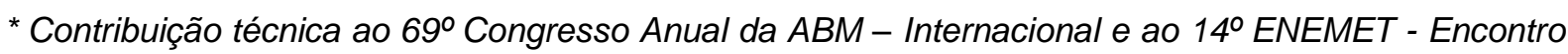
Nacional de Estudantes de Engenharia Metalúrgica, de Materiais e de Minas, 21 a 25 de julho de 2014, São Paulo, SP, Brasil. 


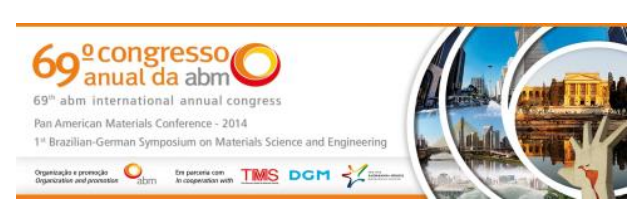

A redução da amplitude do ruído Barkhausen ficou evidente nas amostras expostas a temperaturas de $750^{\circ} \mathrm{C}$ e $850^{\circ} \mathrm{C}$ com tempos de 20 minutos de tratamento térmico, pois foi constatado através das análises complementares através de DRX, metalografia e ferritoscópio que há queda no teor de ferrita. Este comportamento é explicado pela redução da fase ferromagnética e a presença da fase sigma, fase intermetálica, com comportamento paramagnético.

Para tempos de 1, 3, 5 e 10 minutos (nas duas temperaturas) não foi possível correlacionar o sinal do RMB com o teor de ferrita existente nas amostras. Houve precipitação de sigma e o teor de ferrita cai progressivamente com o aumento do tempo de tratamento térmico porém o sinal do envelope do ruído não apresentou esta relação.

Portanto conclui-se que a resposta do RMB é sensível quando há modificações microestruturais do material para tempos de tratamento térmico de 20 minutos com frações de sigma de 11,9\% na amostra 7520 e 14,2\% na amostra 8520, sendo essas frações encontradas por meio de metalografia quantitativa.

\section{Agradecimentos}

A CAPES pela concessão da bolsa de mestrado, ao Laboratório de Dinâmica e Instrumentação - LADIN da Universidade de São Paulo - USP permitindo a realização do ensaio de Barkhausen no equipamento Barktec e a Aperam América do Sul pelo material fornecido.

\section{REFERÊNCIAS}

1 American Society for Metals. Properties and selection: irons, steels, and highperformance alloys.10th ed., vol. 1. Metals Handbook. 1990. p.2007-62.

2 Pohl M, Storz O, Glogowsk T. Effect of intermetallic precipitations on the properties of duplex stainless steel. Materials Characterization. 2007;58:65-71.

3 Loureiro JP. Caracterização do aço inoxidável duplex UNS S31803 pela técnica não destrutiva de correntes parasitas pulsadas [projeto de graduação]. Rio de Janeiro: UFRJ; 2010.

4 Grijalba FAF. Desenvolvimento de ensaio não destrutivo baseado no ruído magnético de Barkhausen para caracterização de tensões elásticas e deformações plásticas em aços [tese de doutorado]. São Paulo: USP; 2010.

5 Michalska J, Sozańska M. Qualitative and quantitative analysis of $\sigma$ and $x$ phases in 2205 duplex stainless steel. Materials Characterization. 2006;56:355-62.

6 Romana R. Cinética de formação de fase sigma entre $700^{\circ} \mathrm{C}$ e $900^{\circ} \mathrm{C}$ no aço inoxidável superduplex UNS S32750 [dissertação de mestrado]. São Bernardo do Campo: FEl; 2009.

7 Magnabosco R. Kinetics of sigma phase formation in a duplex stainless steel. Materials Research. 2009;12(3):321-27.

8 Tavares SSM, Castro JLG, Côrte RRA, Souza VM, Pardal JM. Detecção de pequenos teores de fase sigma e avaliação dos seus efeitos na resistência à corrosão do aço inoxidável duplex UNS S31803. Engevista. 2006;8(2):77-82.

9 Normando PG, Moura EP, Souza JA, Tavares SSM, Padovese LR. Ultrasound, eddy current and magnetic Barkhausen noise as tools for sigma phase detection on a UNS S31803 duplex stainless steel. Materials Science and Engineering. 2010;A527:2886-91.

\footnotetext{
* Contribuição técnica ao $69^{\circ}$ Congresso Anual da ABM - Internacional e ao 14ํㅡㄹ ENEMET - Encontro Nacional de Estudantes de Engenharia Metalúrgica, de Materiais e de Minas, 21 a 25 de julho de 2014, São Paulo, SP, Brasil.
} 